\title{
Cutaneous leiomyosarcoma arising in a smallpox scar
}

Robert A Pol ${ }^{1 *}$, Hilde Dannenberg ${ }^{1}$, Jan-Lukas Robertus ${ }^{2}$ and Robert J van Ginkel ${ }^{1}$

\begin{abstract}
Background: Cutaneous leiomyosarcoma (CLM) is a very rare smooth muscle tumour that accounts for about $2-3 \%$ of all superficial soft tissue sarcomas. Although the development of various malignancies in scar tissue is well known, we report the first case of a CLM developing in a small pox scar.

Case presentation: A 66-year-old man presented with a painless, slow-growing lump in a small pox scar on his left shoulder. Histological biopsies showed the lesion to be a primary, well-differentiated cutaneous leiomyosarcoma. A $\mathrm{CT}$ scan of the thorax was conducted, which showed no signs of metastases. The complete lesion was then surgically excised, and histopathological examination revealed a radically excised cutaneous type leiomyosarcoma After 13 months' review the patient was doing well with no evidence of tumour recurrence.

Conclusions: This is the first report of a CLM arising in a small pox scar. Although the extended time interval between scarring and malignant changes makes it difficult to advise strict follow-up for patients with small pox scars, one should be aware that atypical changes and/or symptoms occurring in a small pox scar could potentially mean malignant transformation.
\end{abstract}

Keywords: Cutaneous leiomyosarcoma, Scar, Small pox, Treatment

\section{Background}

Cutaneous leiomyosarcoma (CLM) is a very rare smooth muscle tumour that accounts for about $2-3 \%$ of all superficial soft tissue sarcomas [1]. CLM presents in persons of all ages but with a peak occurrence between $50-$ 70 years of age. It may occur anywhere on the body with a predilection for the limbs. Clinical appearance of CLM is non-specific with a wide range of differential diagnoses including squamous cell carcinoma, amelanotic melanoma and basal cell carcinoma [2]. Although the development of various malignancies in scar tissue is well known, the highest association is found in chronic burn scars. However, sarcomas develop very rarely in (burn) scars. A case of a CLM developing in a small pox scar is presented. To our knowledge, this is the first report of such an association.

\footnotetext{
* Correspondence: pol.chirurgie@gmail.com

${ }^{1}$ Department of Surgery, University Medical Center Groningen, P.O. Box 30 001, Groningen, RB 9700, The Netherlands

Full list of author information is available at the end of the article
}

\section{Case presentation}

A 66-year-old man was referred to our outpatient clinic by his dermatologist. He presented with a painless, slowgrowing lump in a small pox scar on his left shoulder (Figure 1). Histological biopsies were taken and reviewed by a specialised panel for soft tissue tumours, which showed the lesion to be a primary, well-differentiated cutaneous leiomyosarcoma. On re-examination, a firm, nodular scar was seen with no signs of ulceration. There was no lymphadenopathy in his axilla and/or neck. Additionally, a CT scan of the thorax was conducted, which showed no signs of metastases. The complete lesion was then surgically excised and submitted for further pathological examination (Figures 2 and 3). Histopathological examination revealed a poorly delineated tumour located in the dermis with nodular extension into the superficial subcutis and showing a fasciculated growth pattern of spindle cells with eosinophilic cytoplasm and hyperchromatic, elongated, blunt-ended and pleomorphic nuclei. The mitotic index was less than 10/7 HPF $(1.7 \mathrm{~mm})$. Neoplastic cells showed reactivity to $\alpha$-smooth muscle actin and desmin (Figure 4).

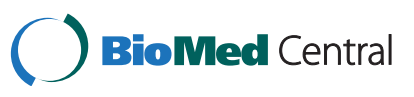

(C) 2012 Pol et al.; licensee BioMed Central Ltd. This is an Open Access article distributed under the terms of the Creative Commons Attribution License (http://creativecommons.org/licenses/by/2.0), which permits unrestricted use, distribution, and reproduction in any medium, provided the original work is properly cited. 


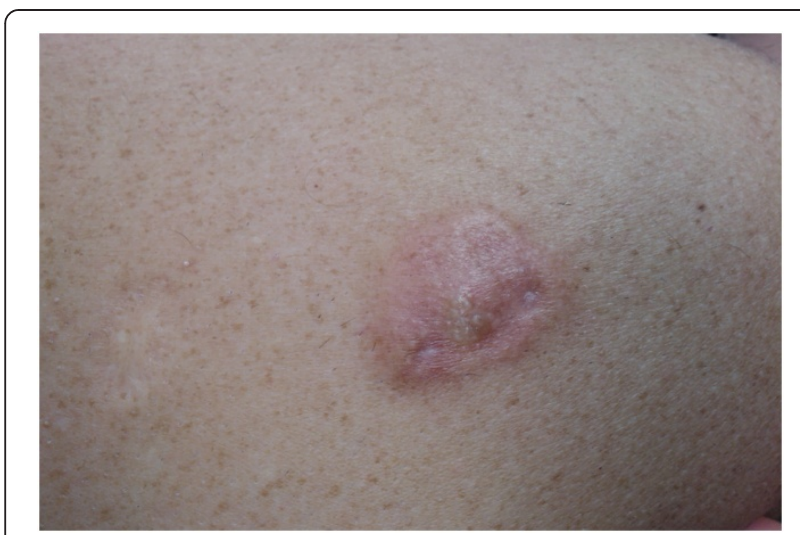

Figure 1 Macroscopic view of the scar. The nodular aspect of the small pox scar is clearly visible.

No necrosis was found. Clear surgical margins ( $>5 \mathrm{~mm}$ ) were confirmed histologically. In conclusion, it concerned a radically excised cutaneous type leiomyosarcoma, Coindre type 1. At 13-month review, the patient was doing well with no evidence of tumour recurrence. A control chest $x$-ray after 6 and 12 months showed no evidence of metastases.

\section{Discussion}

CLM are very rare tumours. They typically present with skin changes such as discolouration and ulceration, and are generally small at presentation $(1-2 \mathrm{~cm})$. Due to their low incidence and atypical presentation, they are often misdiagnosed. The most effective treatment of CLM is wide excision with a $3-5-\mathrm{cm}$ lateral margin and a depth that includes the subcutaneous tissue and fascia $[3,4]$. Local excision without adequate margins leads to recurrence, and increases the risk for metastatic and possibly fatal disease.

Leiomyosarcoma of the skin can be classified as either superficial (cutaneous or subcutaneous) or metastatic leiomyosarcoma from a distant visceral site such as the

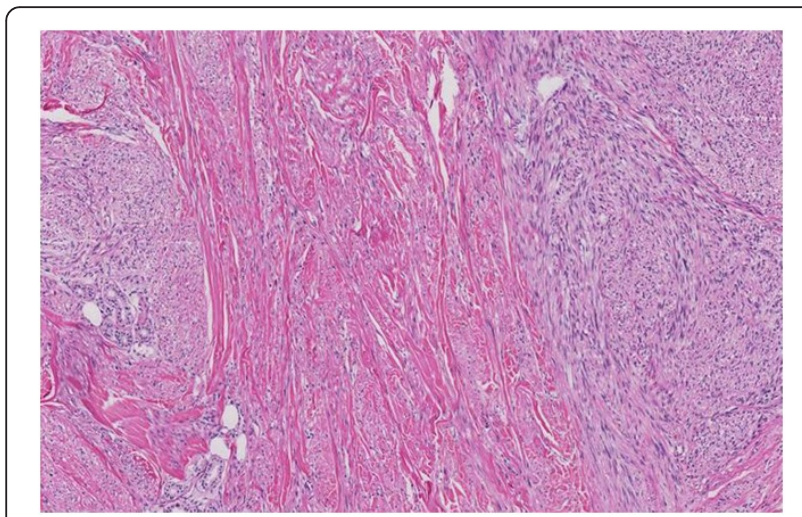

Figure 2 Histopathological features. Dermal proliferation of elongated cells arranged in intersecting fascicles [hematoxylin \& eosin, original magnifications: (Figure 2) $\times 5$; (Figure 3) $\times 20$ ].

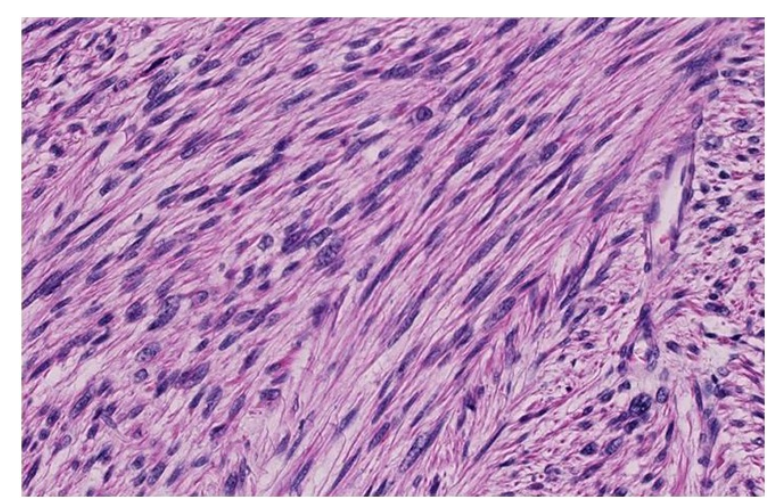

Figure 3 Histopathological features. Dermal proliferation of elongated cells arranged in intersecting fascicles [hematoxylin \& eosin, original magnifications: (Figure 2) $\times 5$; (Figure 3) $\times 20$ ].

uterus or retroperitoneum [2]. Differentiation between the cutaneous and subcutaneous subtypes is not always straightforward, and the distinction is made on the basis of different histological features and biological behaviour [5]. As in our patient, CLM occurs most often on the extremities [6]. The metastatic potential differs significantly between the histological subtypes, with the cutaneous variant having a very low rate of distant metastasis and a local recurrence rate of $30 \%$ [3]. In this specific case, it also concerned a CLM and, because of the clear surgical margins, has an excellent prognosis.

The aetiology of these tumours is relatively unknown, although antecedent traumatic injury, ionising irradiation, chemicals, sunlight and lupus vulgaris have been associated with this type of tumour [7]. We here describe the first patient with CLM arising in a small pox scar. There are various reports on CLM with a similar association with scars [7-9]. The most common association, however, is found in burn scars. The pathogenesis of malignant transformation in burn scars is not known,

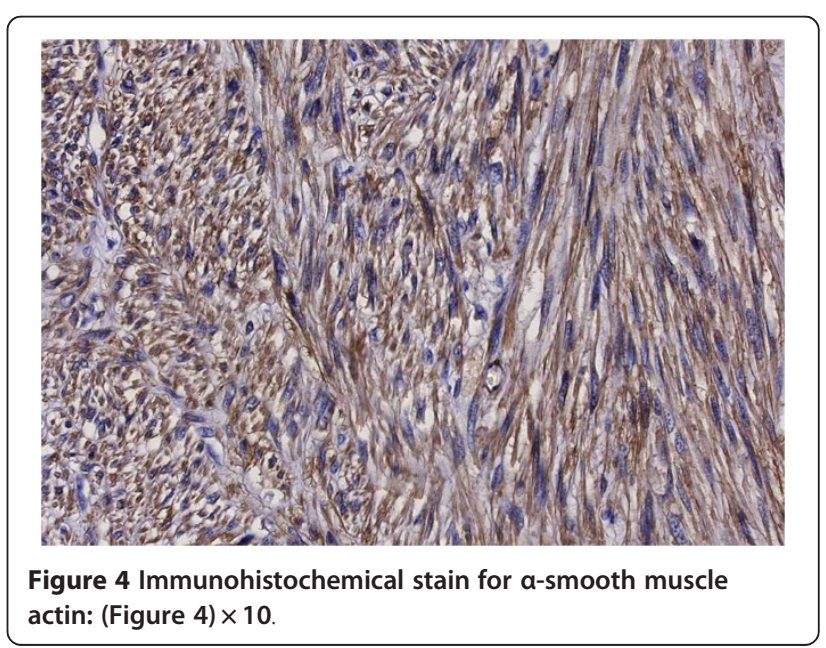


mainly because of the low incidence with only 11 cases reported in the literature [9].

Besides the occasional occurrence of CLM, a familial occurrence of cutaneous leiomyosarcoma with renal cancer has been described in the context of hereditary cutaneous leiomyomatosis and renal cell cancer (HLRCC) [10,11]. This rare inherited tumour syndrome is caused by germ line mutations in the fumarate hydratase $(\mathrm{FH})$ gene [12]. However, mutations in FH do not explain sporadic CLM formation in scar tissue, since aberrant FH expression or somatic mutations are not seen in sporadic tumours $[13,14]$. Adjuvant therapies include radiation therapy, chemotherapy and super voltage cobalt therapy, although CLM has been reported to be both radio- and chemotherapy resistant. [15]

Because this is the first report of a CLM arising in a small pox scar, the presence of a common pathway to malignant transformation with burn scars cannot be determined. Although only a few risk factors have been identified, the most obvious relation with scar tissue has to be the antecedent traumatic injury. The extended time interval between scarring and malignant changes makes it difficult to advise strict follow-up for patients with small pox scars. One should be aware however that atypical changes and/or symptoms occurring in a small pox scar could potentially mean malignant transformation, and adequate diagnostic procedures such as local biopsy and/or primary/secondary wide local excision are the first appropriate steps.

\section{Conclusions}

This report describes the first case of CLM formation in a small pox scar. Primary CLM can be a diagnostic challenge and adequate surgical excision is the appropriate treatment. Based on this one case, regular checks cannot be recommended. However, any change in the existing scar should be followed by a biopsy in order to exclude a sarcoma or make an early diagnosis.

\section{Consent}

Written informed consent was obtained from the patient for publication of this report and accompanying images. A copy of this written consent is available for review by the Editor-in-Chief of this journal.

\section{Competing interests}

The authors declare that they have no competing interest.

\section{Author details}

${ }^{1}$ Department of Surgery, University Medical Center Groningen, P.O. Box 30 001, Groningen, RB 9700, The Netherlands. 'Department of Pathology, University Medical Center Groningen, University of Groningen, Groningen, The Netherlands.

\section{Authors' contributions}

$\mathrm{RP}$ and HD drafted the manuscript. JLR drafted part of the manuscript, critically revised its final form, and provided Figures 2 and 3. RJG critically revised the final manuscript and was responsible for the primary care and outpatient controls. All authors read and approved the final manuscript.

Received: 14 April 2012 Accepted: 16 July 2012

Published: 16 July 2012

\section{References}

1. Zahm SH, Fraumeni JF Jr: The epidemiology of soft tissue sarcoma. Semin Oncol 1997, 24:504-512.

2. Annest NM, Grekin SJ, Stone MS, Messingham MJ: Cutaneous leiomyosarcoma: a tumour of he head and neck. Dermatol Surg 2007, 33:628-633.

3. Kuflik JH, Schwartz RA, Rothenberg J: Dermal leiomyosarcoma. J Am Acad Dermatol 2003, 48:S51-S53.

4. Angeloni M, Muratori F, Magarelli N, Chalidis BE, Ricci R, Rossi B, Maccauro G: Exophytic growth of a neglected giant subcutaneous leiomyosarcoma of the lower extremity. A case report. Int Semin Surg Oncol 2008, 5:11.

5. Bernstein SC, Rienigk RK: Leiomyosarcoma of the skin. Treatment of 34 cases. Dermato/ Surg 1996, 22:631-635.

6. Liao WC, Lin JT, Ma H, Chen WYK, Yeh FL: Primary cutaneous leiomyosarcoma. J Plast Surg Assoc ROC 2003, 12(1):1-10.

7. Gonzales-Sixto B, De la Torre C, Parvadilla R, Carpintero ML: Leiomyosarcoma arising from scofuloderma scar. Clin Exp Dermatol 2008, 33:776-778.

8. Conzales-Vela MC, Val=Bernal JF, Rubio S, Olalla JJ, Gonzales-Lopez MA: Cutaneous leiomyosarcoma developing on a pacemaker pocket. Dermatol Surg 2009, 35:863-867.

9. Can Z, Yilmaz S, Riza A, Erocen, Apaydin I, Kuzu I: Sarcoma developing in a burn scar: case report and review of the literature. Burns 1998, 24:68-71.

10. Toro JR, Nickerson ML, Wei MH, Warren MB, Glenn GM, Turner ML, Stewart L, Duray P, Tourre O, Sharma N, Choyke P, Stratton P, Merino M, Walther MM, Linehan WM, Schmidt LS, Zbar B: Mutations in the fumarate hydratase gene cause hereditary leiomyomatosis and renal cell cancer in families in North America. Am J Hum Genet 2003, 73:95-106.

11. Wei MH, Toure $O$, Glenn GM, Pithukpakorn M, Neckers L, Stolle C, Choyke P, Grubb R, Middelton L, Turner ML, Walther MM, Merino MJ, Zbar B, Linehan WM, Toro JR: Novel mutations in $\mathrm{FH}$ and expansion of the spectrum of phenotypes expressed in families with hereditary leiomyomatosis and renal cell cancer. J Med Genet 2006, 43:18-27.

12. Tomlinson IP, Alam NA, Rowan AJ, Barclay E, Jaeger EE, Kelsell D, Leigh I, Gorman P, Lamlum H, Rahman S, Roylance RR, Olpin S, Bevan S, Barker K, Hearle N, Houlston RS, Kiuru M, Lehtonen R, Karhu A, Vilkki S, Laiho P, Eklund C, Vierimaa O, Aittomäki K, Hietala M, Sistonen P, Paetau A, Salovaara R, Herva R, Launonen V, et al: Germ line mutations in FH predispose to dominantly inherited uterine fibroids, skin leiomyomata and papillary renal cell cancer. Nat Genet 2002, 30:406-410.

13. Barker KT, Spendlove HE, Banu NS, Bridge JA, Fisher C, Shipley J, Garrett M, Manyonda I, Houlston RS: No evidence for epigenetic inactivation of fumarate hydratase in leiomyomas and leiomyosarcomas. Cancer Lett 2006, 235:136-140.

14. Barker KT, Bevan S, Wang R, Lu YJ, Flanagan AM, Bridge JA: Low frequency of somatic mutations in the $\mathrm{FH}$ /multiple cutaneous leiomyomatosis gene in sporadic leiomyosarcomas and uterine leiomyomas. $\mathrm{Br} J$ Cancer 2002, 87(4):446-448.

15. Lin JY, Tsai RY: Subcutaneous leiomyosarcoma on the face. Dermatol Surg 1999, 25:489-491.

doi:10.1186/1477-7819-10-148

Cite this article as: Pol et al.: Cutaneous leiomyosarcoma arising in a smallpox scar. World Journal of Surgical Oncology 2012 10:148. 